\title{
Hangi Kişilik Özelliği Örgütsel Yaratıcılık Üzerinde Daha Etkilidir?1
}

\author{
DOI: 10.26466/opus.586879 \\ *
}

\section{Fatma Yilmaz}

${ }^{* 1}$ Dr. Öğr. Üyesi, Erzincan Binali Yıldırım Üniversitesi, Üzümlü MYO, Üzümlü/Erzincan/Türkiye E-Posta: ffatmaayilmaz@gmail.com

ORCID:0000-0001-8065-7245

\section{Öz}

Örgütsel yaratıcllk, kurumların tüm birim ve süreçlerinde bir bütün şeklinde yaratıcı düşüncenin uygulanmasıdır. Örgütsel yaratıcıllk işletmelerin uzun dönemli rekabet avantajı yaratabilmeleri açısından oldukça önemlidir. Bu çalışmada işgörenlerin kişilik özelliklerinin örgütsel yaratıcılık üzerindeki etkilerinin belirlenmesini amaçlamaktadır. Bu doğrultuda çalışmanın örneklemini bir hizmet işletmesinde çalışan 392 katılımo oluşturmaktadır. Kişilik özellikleri; nörotiklik, dışa dönüklük, gelişime açıklık, uyumluluk ve öz disiplin şeklinde beş boyuttan oluşmaktadır. Demografik değişkenler ve kişilik özellikleri bağımsız değişken iken örgütsel yaratıcılık bă̆ımlı değişkendir. Araştırmada ilk olarak konu ile ilgili literatür taraması yapılmış olup ardından bu boyutlar SPSS paket programı kullanılarak örgütsel yaratıcllk değişkeni ve demografik değişkenler ile ilişkilendirilmiştir. Son bölümünde araştırma bulguları değerlendirilerek katılımcıların kişilik özelliklerine ve bu kişilik özelliklerinin örgütsel yaratıcllk üzerindeki etkilerine ilişkin sonuçlar elde edilmiştir. Bu sonuçlara göre örgütsel yaratıcllk üzerinde sırasıyla; sorumluluk, dışa dönüklük, uyumluluk ve deneyime açıklık kişilik özellikleri etki etmektedir. Ayrıca cinsiyet, medeni durum, çalışma şekli, yaş, eğitim ve çalışma süresinin de kişilk özellikleri ve örgütsel yaratıcllk üzerinde anlaml etkiler yaratı̆̆̆ sonucuna varılmıştır.

Anahtar Kelimeler: Kişilik özellikleri, örgütsel yaratıcllk, beş faktörlü kişilik özellikleri

\footnotetext{
${ }^{1}$ Bu çalışma 18. Uluslararası Iş̧letmecilik Kongresi'nde bildiri olarak sunulmuştur.
} 


\title{
Which Personality is More Effective on Organizational Creativity?
}

\begin{abstract}
Organizational creativity is the application of creative thinking as a whole in all units and processes of institutions. Organizational creativity is very important for enterprises to create a long-term competitive advantage. In this study, it is aimed to determine the effects of personal characteristics of employees on organizational creativity. In this respect, the sample of the study consists of 392 participants working in a service enterprise. Personality characteristics; It consists of five dimensions: neuroticism, extroversion, openness to development, compatibility and self-discipline. While demographic variables and personality traits were independent variables, organizational creativity was dependent variable. In the research, firstly the literature was searched and then these dimensions were related to organizational creativity variable and demographic variables by using SPSS package program. In the last part, the results of the research were evaluated and the results of the personality traits of the participants and the effects of these personality traits on organizational creativity were obtained. According to these results, organizational creativity, respectively; Responsibility, extroversion, compatibility and openness to experience influence personality trait. In addition, it has been concluded that gender, marital status, working style, age, education and working time have significant effects on personality traits and organizational creativity.
\end{abstract}

Keywords: Personality traits, organizational creativity, five-factor personality traits. 


\section{Giriş}

Kişilik Kavramı: Kişilik kavramı en basit haliyle; "bir insanı diğer insanlardan ayıran, o bireye ait davranışlar bütünüdür". Kişilerin davranışlarını, ayırt edici ve kalıcı bir biçimde etkileyen psikolojik faktörler de kişilik kavramını ifade etmektedir (Şahin ve Aksu, 2015: 136). Türk Dik Kurumu'nun tanımına göre kişilik; bir kimseye özgü belirgin özellik, manevi ve ruhsal niteliklerinin bütünü, şahsiyet olarak tanımlanmaktadır. İç ve dış uyarıcıların etkisinde olan kişilik, bireylerin psikolojik, kalıtsal ve edinilmiş olan yeteneklerini, duygu ve isteklerini, güdü ve alışkanlıkları gibi tüm davranışlarını içine almaktadır. Kişiliğin meydana gelmesinde bireylerin doğuştan gelen özellikleri ve içinde bulunduğu çevrenin etkilerini bir arada görmek mümkündür. Bu açıdan bakıldığında, kişiliğin; çevrenin etkisiyle bireye has özellikleri, içinde yaşamış olduğu insan topluluklarının ve insanlarda var olan ortak bir takım özellikleri yansıttığı sonucu çıarılabilmektedir (Yelboğa, 2006,s.198).

Kişilik kavramı genellikle üç başlık altında incelenmiştir. Kişilik genel olarak birçok araştırmacı tarafından karakter, mizaç (huy) ve yetenek boyutları temelinde sınıflandırılmıştır (Tikici ve Deniz, 1991,s.74). Karakter; karakter, bireye özgü olan davranışlardır. Kişilerin duygusal, zihinsel ve bedensel etkinliklerine çevrenin vermiş olduğu değerlerdir. Kişilerin karakterleri bireysel özellikleri ile yaşadıkları çevrenin değer yargılarından oluşmaktadır. (Köknel, 1997,s.20). Karakter olgusu sonradan edinilebilen bir kavram olarak ifade edilebilmektedir (Zangwill, 2009,s.224). Mizaç; izaç veya huy, günlük yaşantıda bireye özgü, sınırlı, duygusal tepkilerin nitelik ve nicelik bakımından değişmesidir. Neşelenmek, sıkılmak, kızmak gibi kişiden kişiye değişen özellikler mizaç ya da huydur (Köknel, 1997,s.19-20). Yetenek; kişiliğin meydana gelmesindeki son bileşen yetenektir. Yetenekler, kişilerin sahip olduğu bedensel ve zihinsel özellikler şeklinde ikiye ayrılmaktadır. Zihinsel yetenekler, kişilerin ilişkileri kavrayabilme, analiz edebilme şeklindeki zihinsel özellikleri ifade etmektedir (Eroğlu, 2011, s.221). Kişilik olgusunun oluşumu ve gelişiminde etkili olan faktörler şunlardır (Luthans, 1995, s.114): Kalıtım faktörleri, sosyo-kültürel faktörler, aile faktörü, sosyal yapı ve sosyal sınıf faktörleri, coğrafi faktörler ve diğer faktörler. 
Beş Faktörlü Kişilik Özellikleri:Norman Anderson kişilik özelliklerini tanımlamada kullanılan 555 sıfatın varlığını ifade etmişlerdir. Araştırmasinda üniversite öğrencilerinden, sıfatlardan her birine sahip olan kişiyi ne kadar sevebileceklerini belirlemelerini istemiştir. 1960 yılında yaptığı bu çalışmada en sevilen kişilik özelliğinin "samimiyet" olduğu görülmüştür. Çalışma sonuçlarına göre öne çıan 60 kişilik özelliği en sevilenden en sevilmeyene göre sıralandığında; samimi, dürüst, anlayışlı, sadık, gerçekçi ve güvenilir sıfatları ilk altı sırada yer almaktadır. Gerçekçi olmayan, dürüst olmayan, zalim, kötü, sahtekar, yalancı özellikleri ise en sevilmeyen ilk altı özelliktir (Güney, 2011,s.55-56). Cüceloğlu, Türkçe 'de kişilik özelliklerinin ifadesi için kullanılan tahmini olarak $10-15$ bin arasında kullanılan sıfatın olduğunu belirtmiştir (Cüceloğlu, 2005,s.418). Kişilik üzerine yapılan tüm çalışmalar özünde beş faktör kişilik kuramına dayanmaktadır (Şentepe ve Güven, 2015,s.28). Beş faktör kişilik kuramı; “Özellikler Yaklaşımı"na dayanan kişiliğin ölçümlenebilmesinde bireylerin hem kendilerini hem de diğer bireyleri ifade etmeisi için çeşitli sıfatlardan yararlanmaktadır (Doğan, 2013,s.57). 1966 y1lında Allport ve Odbert in birlikte yaptıkları çalışmayla araştıılmaya başlanan kişilik özellikleri çalışmalarında Cattel, kişiliği 16 boyutta, Eysenk, içe dönüklük ve dışa dönüklük olmak üzere 2 boyutta açıklamaya çalışmıştır. 1978 yılında Robert R. McCrea ve Paul T. Costa "nın çalışmaları, 1980 yılında aynı araştırmacıların içe dönüklük ve dışa dönüklük boyutlarına üçüncü bir boyut olan deneyime açıklığı eklemesi; 1987 yılında ise dördüncü ve beşinci boyutlar olan uyumluluk ve sorumluluk (vicdanlılık) boyutlarını ekleyerek ve bahsedilen boyutlara yöneltilen eleştiriler doğrultusunda çalışmalarını da genişleterek "Beş Büyük Faktör" kuramını ortaya koymuşlardır (Sayın ve Aslan, 2005). Beş faktör kuramının boyutları şu şekildedir:

- Nörotiklik:Duygusal dengesizlik faktörü nörotisizm olarak da adlandırılmakta olup, duygusal denge, duygusal tutarsızlık, duygusal değişkenlik, duygusal dalgalanma gibi kavramlarla da anılabilmektedir. Çeşitli araştırmalarda öfkeli, endişeli, güvensiz, kendisiyle uğraşan, sinirli, kaygılı, bunalımlı olma, huzursuzluk, karamsarlık, problemli olma, mutsuz olma, depresif, sıkılmış, duygusal, üzgün ve diğerlerine güvenmemek, strese dayanma yeteneği, duygusal iniş- çıkışlar, tedirginlik, huzursuzluk ve sabırsızlık, düşmanlık, kırılganlık, dürtüsellik, 
negatif duyguları deneyimleme eğilimli, rasyonel olmayan düşüncelerle ilgili, başa çıkma mekanizmalarındaki yetersizlikle bağlantılı gibi özelliklerle tanımlanmaktadır (Barrick ve Mount, 1991,s.5). Costa ve McCrae"nin (1992) çalışmalarına göre duygusal dengesizlik, olumlu psikolojik uyum ve duygusal dengenin eksik olma durumunu ifade etmektedir. Costa ve McCrae (1992, s.654) yapmış olduklarıçalışmaların sonucunda nevrotik kişilik yapısı ile ilgili altı adet temel sıfat belirtmişlerdir. Bu sıfatlar şu şekildedir (Costa ve McCrae, 1992,s.654): Endişeli, düşmanca duygulara sahip, depresif, kendinin farkında, düşüncesiz ve kırılgan olmadır. Bu kişiler devamlı endişeli olan, depresyon ile iç içe yaşayan, gerginlik ve öfke duygularından en az birini sürekli hisseden ve bu duyguları hissetmekten keyif alan bireylerdir. Öz saygıları düşük olmakla birlikte gerçek üstü mükemmeliyetçilik inancı olan, karamsar tutumlara sahip, hayatlarını devamlı iniş - çıkışlarla yaşayan kişilerdir ve duygusal denge düzeyleri düşüktür (Bulut, 2017,s.1208).

- Dışa Dönüklük: Dışa dönük bireyler davranışlarını çevreye göre kısıtlamamakta ve rahat davranmaktadırlar. Yaşamaktan keyif alan dışa dönük bireyler genelde iyimser tablolar çizerler ve sıcakkanlı yapıda tavırlar sergilerler (Robbins, 2001,s.95). Yüksek iletişim yetenekleri, kaynakların bulunması ve kullanılması konusunda çevresindekilere göre daha aktif rol alarak gruplarına öncülük edebilirler (Zel, 2001, s.31). Cazip iş ve organizasyonlarda yer alarak karşılarına çıkan fırsatları değerlendirirler. Çevresindekilerin ilgisini çekme hususunda başarılı olan bu kişilik özelliğine sahip bireyler toplantı ve benzeri kalabalık ortamlarda bulunmayı istemektedirler (Deniz ve Erciş, 2008,s.301-330). Dışadönük bireyler, kendine güvenen, cana yakın, neşeli, heyecan arayan, baskın, ilişkilerinde rahat, dış dünyayla açık bir etkileşim kuran, insanlarla birlikte olmaktan eğlenen, grup içinde konuşmayı seven, kendilerini ön plana çıkaran ve ilgi çeken kişilerdir (Lounsbury, vd., 2002,s.67).

Dışadönüklük düzeyi düşük bireyler ise; sosyalleşmekten mutlu olmayan, diğerlerine karşı mesafeli olan, utangaç ve sessiz kalmayı tercih eden kişiler biçiminde tanınmaktadırlar (Doğan, 2013,s.57). Gerçekleştirilen araştırmalarda, dışa dönüklük derecesi yüksek olan bireylerin yaptıkları işlerdeki performansların da yüksek olduğu ortaya 
çıkmıştır arasında (Hurtz ve Donovan, 2000,s.871). McCrae ve Costa (1992, s.654) yapmış oldukları çalışmaların neticesinde dışa dönük kişilik özellikleriyle ilgili altı adet temel sıfatın kullanılabileceğini belirtmişlerdir. Bu sıfatlar şu şekildedir:

- Girişken olma (neşeli ve birçok arkadaşı bulunan),

- Aktif olma (enerjik ve hızlı hareket edip, hızlı yürüyen)

- İddialı olma (sözü geçen ve kuvvetli),

- Maceracı-heyecan odaklı olma (gösterişli),

- İyimser (güler yüzlü ve cesur)

- Sıcakkanlı olma (sempatik ve konuşkan) bu sıfatlar dişa dönük kişilik özelliklerini tanımlamaktadırlar.

- Gelişime Açılılı: Gelişime/deneyime açıklık eğilimi yüksek olan bireyler kişilik olarak geleneksel cinsiyet rollerini reddetmektedirler ve yeni şeyler yaşamaya karşı ilgili yapıdadırlar. Kendilerini tanımlamada bağımsızlığı ve kendine özgü olmayı vurgulamaktadırlar. Çeşitliliği tek tip olmaya tercih etmektedirler ve cesurdurlar (Costa ve McCrae, 1992,s.657-659). McCrae ve Costa 1985 ve 1992 yıllarında yaptıkları çalışmaların sonucunda deneyime açık kişilik yapısı kapsamında altı tane temel sıfat belirtmişlerdir. Bu sıfatlar şu şekildedir (McCrae ve Costa, 1992, s.654): Duygusal, fikir sahibi, estetik, aktif, fantastik, ve değer sahibi olmadır.

- Uyumluluk: Uyumluluk özelliği yüksek olan bireyler birlikte çalışmaktan keyif alan, insanlarla geçim sorunu hissetmeyen, ilişkilerinde kibarlığ ön planda tutan ve gruplarındaki kişilere arkadaşça yaklaşan bireylerdir. İçinde bulundukları sosyal topluluklarda güveni hissettirirler. Hoşgörüleri oldukça geniş olan uyumlu bireylerin yumuşak bir kalpleri vardır. Uyumluluk özelliği yüksek olan yöneticiler astları motive etmede sorunsuzdurlar ve bu görevde başarılı olma şansları yüksektir. Hassasiyetleriyle ihtiyaç sahibi kimselere yardımcı olmak konusunda fayda sağlarlar (Zel, 2001,s.31). Uyumluluk boyutunun birçok araştırmacı tarafından benzer ve farklı sıfatlarla tarif edildiği görülmektedir. Uyumluluk faktörü sempatik, sevecen, sicakkanlı ve cömert genel olarak saygıll, , yardımsever ve diğerlerinin istekleriyle uzlaşmaya hazır, insan doğası hakkında iyimser görüşe sahip, insanların dürüst, saygın (Goldberg, 1990,s.1218), 1lımlı, kibar, arkadaş canlısı, 
duygusal, güvenilir, fedakar, yumuşak kalpli, hoşgörülü insanlar olarak görülmektedirler (Bono, vd., 2002,s.318). McCrae ve Costa, $(1992$, s.654) yapmış oldukları çalışmaların sonucunda uyumlu kişilik yapısı ile ilgili altı adet temel sıfat belirtmişlerdir. Bu sıfatlar: Güvenilir, dürüst, diğergam (yer yer başkalarını kendinden daha önce düşünen), uyumlu, alçak gönüllü ve yumuşak huylu olmadır. Uyumluluk faktörü dışa dönüklük faktörü gibi kişiler arası ilişkilere bağlı olan bir boyut olarak görülmektedir. Fakat dışa dönüklük faktörü sosyal çevre ile bağlantılı iken uyumluluk faktörü ilişkilerin niteliğiyle ilişkilidir (Costa, vd., 1991,s.888).

- Sorumluluk: Beş faktör kişilik kuramı boyutlarından, sorumluluk boyutu; görev bilinciyle hareket etme, azim gösterme (Patrick, 2010,s.241), bilinçlilik, başarılı yönelim, düzenlilik, etkili olma, planlılık, sorumluluk, mükemmeliyetçilik ve çok çalışkanlık gibi belirgin özellikleri kapsamaktadır (McCrae ve John, 1992). Sorumluluk boyutu, zekânın nesnel ölçümleri ile değil, toplumda akıllıca ve zekice olarak değerlendirilen davranışlarla yakından ilişkili olarak öne çıkmaktadır (Barrick ve Mount, 1991). McCrae ve Costa (1992) ve Costa McCrae ve Dy'nin 1991 yılında yapmış oldukları çalışma sonucunda sorumluluk boyutunu tanımlayıcı altı tane sıfatın olduğunu belirtmişlerdir. Bu sıfatlar şu şekildedir; görev bilincine sahip, düzenli, kabiliyetli, ihtiyatlı, başarmak için mücadele güdüsüne sahip, öz disiplinli olmadır. Bu sıfatlar beş faktör kişilik özellikleri kuramının sorumluluk boyutunu tanımlamaktadır. Aynı zamanda bu faktör, beklenenin üzerinde bir performansta çalışmayı, kararlı durmayı, dikkatli olmayı, sorunlarla mücadele edebilmek için her şeye hazırlıklı olmayı, dikkatlice düşünmeyi ve başlanmış olan bir işi yarım bırakmama gibi eğilimleri de ifade etmektedir. Sorumluluğu yükselen kişilerin motivasyon ve iş tatminleri de yükselmektedir (Somer, 1998,s.42).

Beş faktör modelinin \%40-60 oranında kalıtsal nitelikte olduğunu ve özellikle faktörler arasında nevrotiklik ve dişa dönüklük kavramlarına ilişkin kalıtım özelliklerinin diğer faktörlere göre daha belirgin bir şekilde öne çıtığı belirtilmektedir (Garcia, 2011,s.999-1017).

Örgütsel Yaratıcılık: Yaratıcılık; sorunlara, aksaklıklara, bilgideki eksikliğe, uyumsuzluklara karşı duyarlı olma ve güçlükleri tanımlama, çözümler arama, çeşitli tahminlerde bulunma, eksikliklere ait fikirler 
geliştirebilme, ardından da sonucu ortaya koymadır (Sungur, 1992, s.20). Yaratıcılık kavramının temelinde insan olmasına karşılık, işletmelerin ana kaynağının birey olması ve işletmelerin de insanlar tarafından yönetilmesiyle örgütsel boyutta da ele alınan bir kavramdır (Bharadwaj ve Menon, 2000,s.425). Örgütsel yaratıcılık; iş görenlerin içinde var olan potansiyelleri harekete geçirebilen ve yaratıcılık yetisini tüm iş görenleri kapsayacak bir biçimde örgüt geneline yayabilme olarak tanımlanmaktadır (Gürüz ve Özdemir, 2006,s.366). Örgütler, hızla değişen çevreye uyum sağlayabilmek ve örgütü canlı tutabilmek adına yaratıcılığa ihtiyaç duymaktadırlar. Çünkü hızla değişen çevrelerde yaratıcllıktan yoksun olan işletmeler yok olmayla karşı karşıya kalmaktadırlar (Fisk, 2011,s.58).

Barron ve Harrington (1981), 15 yıllık gözlem sonuçlarına dayalı olarak farklı alanlarda yaratıcılığı yüksek olan bireyleri ilgi alanları yaygın, içsel olarak motiveli, yüksek estetik kriterlere sahip, enerjik, risk alabilen, bağımsız karar verebilen, kendine güvenli, sorgulayıcı, farklı bakış açıları geliştirebilen bireyler olarak tanımlamıştır. Feist (1998) ise bir derleme çalışmada sanat ve bilim alanında yaratıcı başarısı yüksek olan bireylerin özelliklerini toparlamıştır. Bilim adamlarının yeni deneyimlere açık, daha gelenekçi, kendine güveni yüksek, öz - algı düzeyi yüksek, içsel yönelimli, hırslı, saldırgan, içsel yönelimli olduğunu bildirmiştir. Sanatçlların ise daha duyuşsal, durağan olmayan bir duygu durum hali, sosyal becerileri daha düşük ve bilim adamlarına göre grup tarafından daha az kabul gören bireyler olduğu belirlenmiştir. Sak'ın (2016) derleme çalışmasında da en sık bahsedilen özellikler orijinal düşünme, yüksek zekaya sahip olma, yaratıcı farkındalık, mantıksal ve sıradışı düşünme, gelişmiş sorgulama becerileri, bilgi ve tecrübe sahibi olma, bağımsız karar verme, risk alma, enerjik olma, meraklı olma, espritüel olma, bilinmeye karşı ilgi duyma, gelişmiş hayal gücü, estetik duyarlılık, açık görüşlülük, yalnız kalma ihtiyac1, sezgisel, duygusal ve gelişmiş etik değerlere sahip olma biçiminde özetlenmiştir

Yaratıcı örgüt özelliklerini geliştirmek için yöneticilerin aşağıdaki hususlara özellikle dikkat etmeleri gerekmektedir (Y1lmaz ve Izgar, 2009,s.947):

- Bireylere yeni fikirleri açıklama ve düşünceleri yaşama aktarma konusunda imkan verilmelidir. 
- Işgörene örgütün iç yaşamını değiştirme ve buna ilişkin projeler yapma hakkı verilmelidir.

- İşgörenlerin yönetimin getirdiğgi gelenek ve kurallara uymaları zorlanmamalıdır. Aksine bir ölçüde belirsizlikler yaratarak yaratıcılıklarını sınamalarını ve örgütsel gelişime katkı yapmalarına izin verilmelidir.

- Daha özgürlükçü, kendini ifade etmeye olanak tanıyan ve kendi kararlarından yola çıkarak örgütsel gelişime katkı sağlayan bir çalışma ortamı yaratılmalıdır.

- Görece, esnek normlara ve değerlere sahip ve işgörene çekici gelebilecek bir iş ortamı yaratılmalıdır.

Örgütsel yaratıcılığın arttırılması için yaratıcılığı desteklemek en önemli husus olarak görülmektedir. Şekil 1'de Woodman ve diğerlerinin öne sürdüğ̈̈ yaratıcılık modeli görülmektedir.

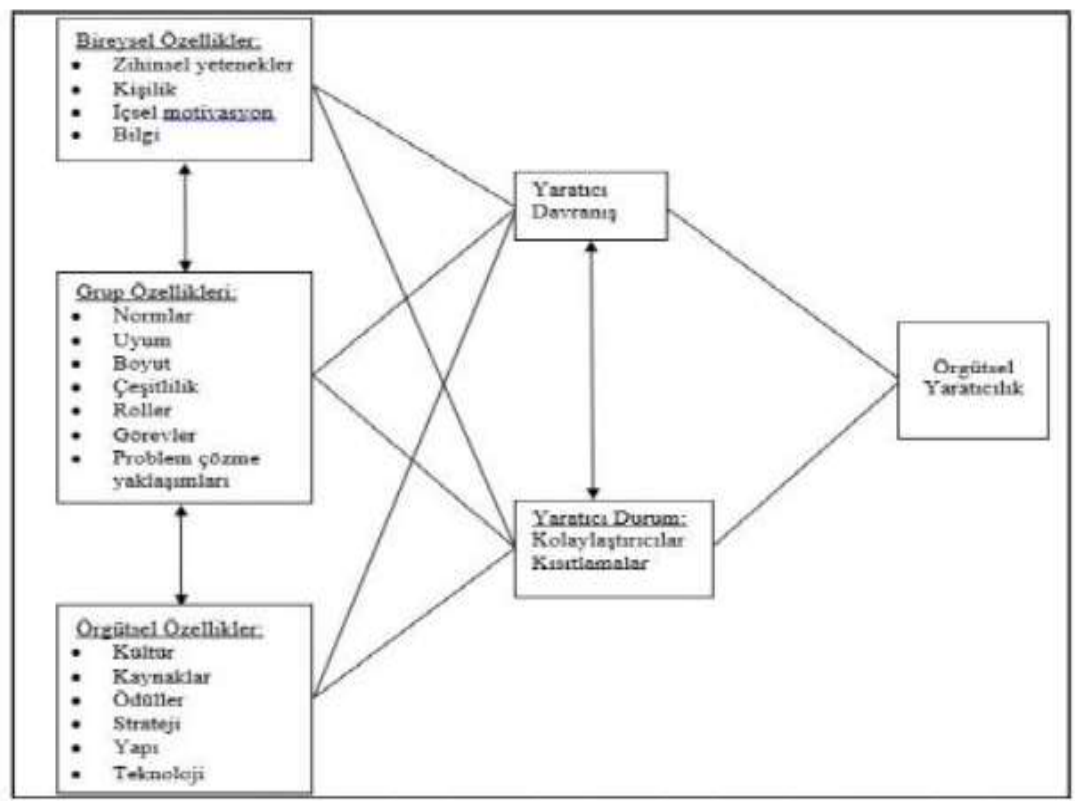

Şekil 1: Yaratıcı Bireyler, Süreç ve Durumlar ile Ürünler Arasındaki İlişkiler

(Woodman, Sawyer ve Griffin, 1993, s.293-321)

Şekil 1'e göre bireysel, grupsal ve örgütsel özellikler bireylerde yaratı davranışı ve yaratıcı durumu etkilemektedir. Böylece de örgütsel 
yaratıcılık ortaya çıkmaktadır. Woodman ve diğerleri (1993) örgütsel yaratıcılık kavramını kompleks sosyal sistemler içerisinde birlikte çalışan kişiler tarafından oluşturulan yararlı, ve değerli; yeni fikirler, ürünler, hizmetler ya da süreçler şeklinde tanımlamaktadırlar. Örgütsel yaratıcılık durumu var olan fiziksel, sosyal, teknolojik vb. sinırlardan daha da ileri gidebilmeyi gerektirmektedir (Woodman, vd., 1993,s.293)

Yaratıcı örgülerin temel özellikleri şu şekilde sıralanabilir (Akat vd., 2002,s.442):

- İletişim kanalları açıtır.

- -Örgüt, bünyesinde yer alan değişik özellikteki bireylerden faydalanılmaktadir.

- Terfiler liyakata göre yapılmaktadır.

- Temel araştırmalara yatırım yapmaktadırlar.

- Merkeziyetçi olmayan bir yapıya sahiptirler.

- Özgün ve farklı amaçları vardır.

Örgütsel yaratıcıllğın yönetilebilmesi, örgütlerdeki yönetsel görevleri tekrardan organize ederek başarılı bir şekilde yönetebilme sürecidir. Örgütsel yaratıcılığın gerçekleşebilmesi için, öncelikle işgörenlerde yaratıcılığın oluşması gerekmektedir. Bu yaratıcılığın gelişebilmesinde ise; kararlılık, azim, cesaret, vizyonel bakış açısı, kültürel birikim, bütünsel ve özgür düşünebilme gereklidir (Marşap, 1999,s.51).

\section{Yöntem, Amaç, Örneklem ve Veri Toplama Aracı}

$\mathrm{Bu}$ çalışmanın amacı bireylerin kişilik özelliklerinin örgütsel yaratıcılık üzerine olan etkisinin belirlenmesi ve katılımcıların demografik özelliklerinin kişilik tarzları üzerindeki etkilerinin araştırılması ve ortaya çıkarılmasıdır. Araştırma sonucu elde edilecek olan bulguların konuya ilişkin yapılacak olan gelecek araştırmalarda bir veri teşkil edecektir.

Araştırma Erzincan ilinde hizmet sektöründe faaliyet gösteren bir işletmedeki bireyler üzerinde gerçekleştirilmiştir. Araştırmada "kolayda örnekleme yöntemi" kullanılmış olup anketlerin çoğu elden dağıtılmış ve geri toplanmıştır. Araştırmada dağıtılan anket formlarının 392'si geri dönmüş ve değerlendirmeye alınmıştır.

Araştırmada veri toplama aracı olarak anket yöntemi kullanılmıştır. Anket formu toplam 86 sorudan oluşmaktadır. Anket formunun birinci 
bölümünde kişisel bilgilerle ilgili 4 soru; İkinci bölümde kişilik özellikleri ile ilgili 44 soru ve örgütsel yaratıcılık ile ilgili 38 soru bulunmaktadır.

Çalışmada katılımcıların kişilik özelliklerini belirlemek amacıyla Benet-Martinez ve John tarafından "beş faktör envanteri" ismiyle geliştirilen ve 44 sorudan meydana gelen ölçek kullanılmıştır. Ölçekte nörotiklik, dışa dönüklük, gelişime açıklık, uyumluluk ve sorumluluk şeklinde beş alt boyut bulunmaktadır. Örgütsel yaratıcılık ölçeği olarak Balay (2010) tarafından geliştirilen 38 maddelik örgütsel yaratıcılık ölçeği kullanılmıştır. Ölçek bireysel yaratıcılık, yönetsel yaratıcılık ve toplumsal yaratıcılık şeklinde üç alt boyuttan oluşmaktadır.

\section{Araştırmanın Modeli ve Hipotezler}

Anket çalışması ile katılımcıların kişilik özelliklerinin örgütsel yaratıcılık üzerindeki etkileri belirlenmeye çalışılmıştır. Araştırmamıza ilişkin model Şekil 1'de gösterilmektedir. Kişilik özellikleri bağımsız değişken olarak örgütsel yaratıcılık ise bağımlı değişken olarak değerlendirilmiştir.

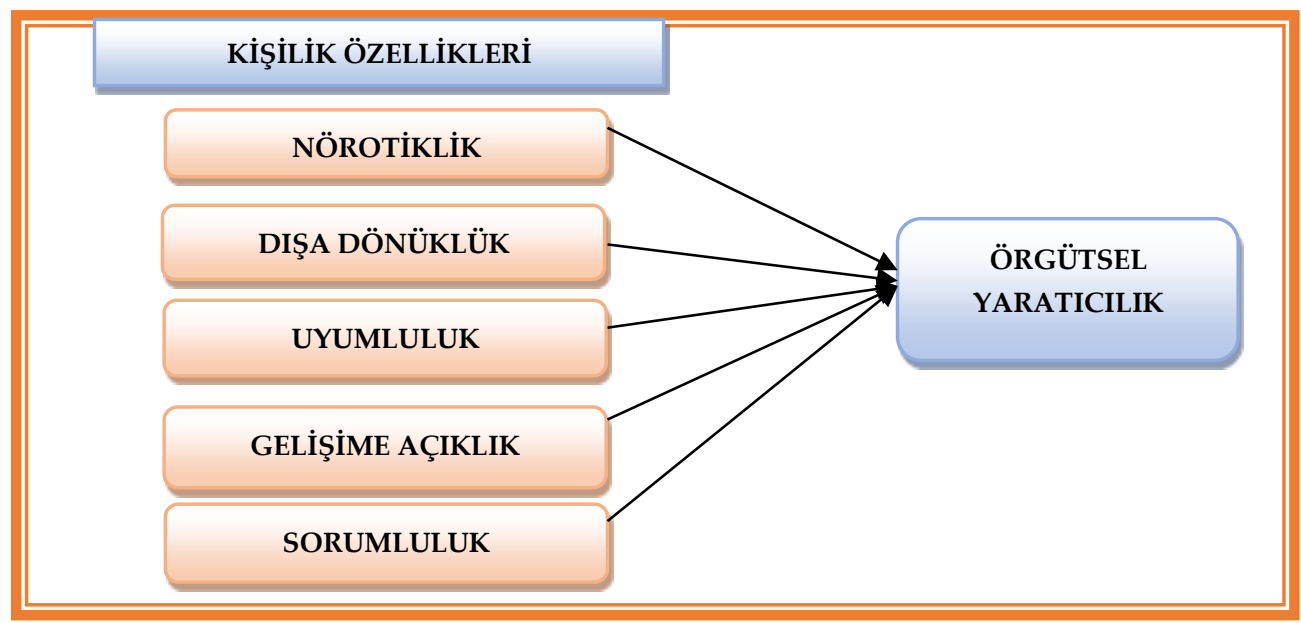

Şekil 1: Araştırma Modeli

Araştırmanın amacına hitap etmesi bakımından belirlenen hipotezler aşağıdaki gibidir: 
- H1: Nörotiklik örgütsel yaratıcılık üzerinde istatistiki olarak anlamlı bir etkiye sahiptir.

- H2: D1şa dönüklük örgütsel yaratıcılık üzerinde istatistiki olarak anlamlı bir etkiye sahiptir. H3: Gelişime açıklık örgütsel yaratıcılık üzerinde istatistiki olarak anlamlı bir etkiye sahiptir.

- H4: Uyumluluk örgütsel yaratıcılık üzerinde istatistiki olarak anlamlı bir etkiye sahiptir.

- H5: Sorumluluk örgütsel yaratıcılık üzerinde istatistiki olarak anlamlı bir etkiye sahiptir.

\section{Güvenilirlik Analizi ve Bulgular}

Balay (2010) tarafından gerçekleştirilen "bireysel, yönetsel ve toplumsal" alt boyutlardan oluşan örgütsel yaratıcılık ölçeği'nde yer alan her bir maddenin faktör yük değerleri .47 ile .88 arasında değişmektedir, iç tutarlık katsayısı (alfa) alt boyutlar için; Bireysel boyut .92, Yönetsel boyut .93, Toplumsal boyut .95 olarak bulunmuştur. Ölçeğin açıkladığı toplam varyans ise \%58'dir (Balay, 2010: 59-61). Beş faktör kişilik ölçeği için; Benet Martinez ve John (1998) yaptıkları çalışmada alt ölçekler için Cronbach alfa değerlerini 0,80 ile 0,90 arasında bulmuştur. Türkçeye çevrilerek kültürlerarası bir çalışmada kullanılan Beş Faktör Kişilik Envanteri'nin Türk örneklemi için yapılan çalışmada alt ölçeklere ait Cronbach alfa değerleri 0,64 ve 0,77 arasında değişmektedir (Sümer, vd.: 2005).

Katılımcıların demografik özelliklerine ait bulgular: \%61,2'si 18-30 yaş aralığında ( $\mathrm{n}=240), \% 29,6$ 'sı 31-43 yaş aralığında $(\mathrm{n}=116), \% 9,2$ 'si ise 44 yaş ve üzeri ( $n=36)$ yaş grubundadır; \%30,6'sı kadın $(n=120)$, \%69, $4^{\prime}$ ü ise erkektir ( $\mathrm{n}=272)$; eğitim durumuna bakıldığında \%38,3'ü ilköğretim $(\mathrm{n}=150), \% 38,0^{\prime} 1$ ortaöğretim $(\mathrm{n}=149), \% 23,7^{\prime}$ si ön lisans ve lisans $(\mathrm{n}=93)$, mezunudur; katılımcıların \%58,7'si bekar $(\mathrm{n}=230), \% 41,3$ '̈ ise evlidir $(\mathrm{n}=162)$.

Yapılan $\mathrm{t}$ testi ve varyans analizlerine göre bazı demografik faktörler ile katılımcıların kişilik özellikleri arasında anlamlı farklılıklar tespit edilmiştir.

Grup istatistiklerine bakıldığında yapılan analizlerde; 
Tablo 1. Katılımcıların Cinsiyetleri ile Kişilik Özellikleri Alt Boyutlarn ve Örgütsel Yaratıcılığa İlişkin T-Testi Sonuçları

\begin{tabular}{|c|c|c|c|c|c|}
\hline Değişken & Cinsiyet & $\mathbf{N}$ & $\overline{\mathbf{x}}$ & $\mathbf{T}$ & Sig. (p) \\
\hline \multirow[t]{2}{*}{ Nörotiklik } & Erkek & 272 & 14,7333 & \multirow[t]{2}{*}{1,489} & \multirow[t]{2}{*}{0,139} \\
\hline & Kadın & 120 & 14,0846 & & \\
\hline \multirow{2}{*}{$\begin{array}{l}\text { Dişa } \\
\text { Dönüklük }\end{array}$} & Erkek & 272 & 29,6250 & \multirow[t]{2}{*}{0,704} & \multirow[t]{2}{*}{0,508} \\
\hline & Kadın & 120 & 29,2904 & & \\
\hline \multirow{2}{*}{$\begin{array}{l}\text { Gelişime } \\
\text { Açıklık }\end{array}$} & Erkek & 272 & 42,6500 & \multirow[t]{2}{*}{$-1,518$} & \multirow[t]{2}{*}{0,126} \\
\hline & Kadın & 120 & 43,4632 & & \\
\hline \multirow[t]{2}{*}{ Uyumluluk } & Erkek & 272 & 30,7083 & \multirow[t]{2}{*}{$-6,758$} & \multirow[t]{2}{*}{0,000} \\
\hline & Kadın & 120 & 34,3971 & & \\
\hline \multirow[t]{2}{*}{ Sorumluluk } & Erkek & 272 & 26,7333 & \multirow[t]{2}{*}{$-3,383$} & \multirow[t]{2}{*}{0,002} \\
\hline & Kadın & 120 & 29,0515 & & \\
\hline \multirow{2}{*}{$\begin{array}{l}\text { Örgütsel } \\
\text { Yaratıcılık }\end{array}$} & Erkek & 272 & 127,4167 & \multirow[t]{2}{*}{$-5,140$} & \multirow[t]{2}{*}{0,000} \\
\hline & Kadın & 120 & 138,1471 & & \\
\hline
\end{tabular}

Tablo 1 incelendiğinde; uyumluluk sorumluluk ve örgütsel yaratıcılık değişkenlerinde anlamlı bir ilişkinin varlığından söz edilebilmektedir $(p<0,05)$. Ortalamalara göre kadınların erkeklere göre kişilik tarzı olarak daha uyumlu, daha çok sorumluluk sahibi oldukları erkeklerin ise örgütsel anlamda daha yaratıcı olduğu söylenebilir.

Tablo 2. Katılımcıların Medeni Durumları ile Kişilik Özellikleri Alt Boyutları ve Örgütsel Yaratıcıliğa İlişkin T-Testi Sonuçları

\begin{tabular}{|c|c|c|c|c|c|}
\hline Değişken & $\begin{array}{l}\text { Medeni } \\
\text { Durum }\end{array}$ & $\mathbf{N}$ & $\overline{\mathbf{X}}$ & $\mathbf{T}$ & Sig. (p) \\
\hline \multirow[t]{2}{*}{ Nörotiklik } & Evli & 162 & 14,1235 & \multirow[t]{2}{*}{$-0,663$} & \multirow[t]{2}{*}{0,508} \\
\hline & Bekar & 230 & 14,3957 & & \\
\hline \multirow{2}{*}{$\begin{array}{l}\text { Dişa } \\
\text { Dönüklük }\end{array}$} & Evli & 162 & 31,0000 & \multirow[t]{2}{*}{6,280} & \multirow[t]{2}{*}{0,000} \\
\hline & Bekar & 230 & 28,2609 & & \\
\hline \multirow{2}{*}{$\begin{array}{l}\text { Gelişime } \\
\text { Açıklık }\end{array}$} & Evli & 162 & 43,9012 & \multirow[t]{2}{*}{2,366} & \multirow[t]{2}{*}{0,018} \\
\hline & Bekar & 230 & 42,7304 & & \\
\hline \multirow[t]{2}{*}{ Uyumluluk } & Evli & 162 & 34,7284 & \multirow[t]{2}{*}{4,741} & \multirow[t]{2}{*}{0,000} \\
\hline & Bekar & 230 & 32,2391 & & \\
\hline \multirow[t]{2}{*}{ Sorumluluk } & Evli & 162 & 30,9074 & \multirow[t]{2}{*}{7,315} & \multirow[t]{2}{*}{0,000} \\
\hline & Bekar & 230 & 26,5348 & & \\
\hline \multirow{2}{*}{$\begin{array}{l}\text { Örgütsel } \\
\text { Yaratıcılık }\end{array}$} & Evli & 162 & 146,7901 & \multirow{2}{*}{11,703} & \multirow{2}{*}{0,000} \\
\hline & Bekar & 230 & 126,4609 & & \\
\hline
\end{tabular}


Katılımcıların medeni durumlarına ilişkin t-testi sonuçlarına göre; evli katılımcıların kişilik özellikleri bakımından dışadönük, gelişime açık, uyumlu ve sorumluluk sahibi olduğu bunun yanında örgütsel yaratıcılıklarının da bekar katılımcılara göre daha yüksek olduğu görülmektedir.

Tablo 3. Katılımcıların Yaşları ile Kişilik Özellikleri Alt Boyutları ve Örgütsel Yaratıcılı̆̆a İlişkin Anova Sonuçları

\begin{tabular}{|c|c|c|c|c|c|c|}
\hline \multicolumn{7}{|l|}{ ANOVA } \\
\hline & & \multicolumn{2}{|l|}{ Kareler } & \multicolumn{3}{|l|}{ Ortalama } \\
\hline & & Toplamı & df & Karesi & $\mathbf{F}$ & $\mathrm{p}$ \\
\hline \multirow[t]{3}{*}{ Nörotiklik } & Gruplar Arası & 89,314 & 2 & 44,657 & 2,819 & ,061 \\
\hline & Gruplar İçi & 6162,254 & 389 & 15,841 & & \\
\hline & Toplam & 6251,569 & 391 & & & \\
\hline Dişa & Gruplar Aras1 & 65,092 & 2 & 32,546 & 1,539 & ,216 \\
\hline \multirow[t]{2}{*}{ Dönüklük } & Gruplar İçi & 8228,408 & 389 & 21,153 & & \\
\hline & Toplam & 8293,500 & 391 & & & \\
\hline Gelişime & Gruplar Arası & 170,939 & 2 & 85,469 & 3,679 & ,063 \\
\hline \multirow[t]{2}{*}{ Açıklık } & Gruplar İçi & 9037,061 & 389 & 23,232 & & \\
\hline & Toplam & 9208,000 & 391 & & & \\
\hline \multirow[t]{3}{*}{ Uyumluluk } & Gruplar Arası & 252,791 & 2 & 126,396 & 4,659 & , 010 \\
\hline & Gruplar İçi & 10554,084 & 389 & 27,131 & & \\
\hline & Toplam & 10806,875 & 391 & & & \\
\hline \multirow[t]{3}{*}{ Sorumluluk } & Gruplar Arası & 221,370 & 2 & 110,685 & 2,783 & , 026 \\
\hline & Gruplar İçi & 15472,824 & 389 & 39,776 & & \\
\hline & Toplam & 15694,194 & 391 & & & \\
\hline Örgütsel & Gruplar Arası & 11948,466 & 2 & 5974,233 & 16,696 & ,000 \\
\hline \multirow[t]{2}{*}{ Yaratıcılık } & Gruplar İçi & 139190,096 & 389 & 357,815 & & \\
\hline & Toplam & 151138,561 & 391 & & & \\
\hline
\end{tabular}

Tablo 3 incelendiğinde uyumluluk, sorumluluk ve örgütsel yaratıcılık alt boyutlarında $\mathrm{p}<0,05$ bulunmuştur böylece \%95 güven düzeyinde katılımcıların yaşları ile kişilik tarzları alt boyutlarından uyumluluk ve sorumluluk arasında anlamlı bir fark vardır. Nörotiklik, dışa dönüklük ve gelişime açıklık alt boyutları arasında ise anlamlı bir ilişki bulunamamiştır. 
Tablo 4. Katılımcıların Yaşlan ile Uyumluluk Boyutu Arasındaki Tukey Testi Sonuçları

\begin{tabular}{llcc}
\hline \multicolumn{3}{c}{ Uyumluluk } \\
\hline Tukey HSD ${ }^{\mathrm{a}, \mathrm{b}}$ & \multicolumn{2}{c}{ Subset for alpha $=0.05$} \\
\hline Yaş & $\mathbf{N}$ & $\mathbf{1}$ & $\mathbf{2}$ \\
\hline $18-30$ & 240 & 32,8125 & \\
\hline $31-43$ & 116 & 33,4828 & 35,6111 \\
\hline 44 yaş ve üzeri & 36 & & $\mathbf{1 , 0 0 0}$ \\
\hline Sig. & & $\mathbf{7 1 4}$ &
\end{tabular}

Anlamlı farklılığın hangi gruptan kaynaklandığını anlamak için Tukey testi sonuçları dikkate alındığında farklılığın 44 yaş ve üzeri yaş grubunda olanlardan kaynaklandığ görülmektedir. 44 yaş ve üzeri yaş grubu uyumlu kişilik özelliğini diğer yaş gruplarına göre daha çok sergilemektedir. Yaş ile birlikte uyumluluk özelliği de artmaktadır.

Tablo 5. Katılımcıların Yaşlan ile Sorumluluk Boyutu Arasındaki Tukey Testi Sonuçları

\begin{tabular}{lccc}
\hline Sorumluluk & & \\
\hline Tukey HSD ${ }^{\mathrm{a}, \mathrm{b}}$ & & & \\
\hline & $\mathbf{N}$ & $\mathbf{1}$ & $\mathbf{2}$ \\
\cline { 3 - 4 } Yaş & 240 & 27,9125 & \\
\hline $18-30$ & 116 & 28,5517 & 28,5517 \\
\hline $31-43$ & 36 & & 30,5278 \\
\hline 44 yaş & &, 811 &, 139 \\
ve üzeri & & & \\
\hline Sig. & & & \\
\hline
\end{tabular}

Tablo 5'te tukey testi sonuçları verilmektedir. Sorumluluk kişilik tarzının 44 yaş ve üzeri yaş grubunda daha yüksek olduğu görülmektedir. Yaş ilerledikçe sorumluluk da artmaktadır.

Tablo 6'da yaş değişkeni ve örgütsel yaratıcılığa ait tukey testi sonuçlarına yer verilmiştir. Anlamlı farklılık44 yaş ve üzeri yaş grubundan kaynaklanmaktadır. 44 yaş ve üzerinde örgütsel yaratıcılık daha fazladır. Yaş arttıkça örgütsel yaratıcılık da artmaktadır. 
Tablo 6. Katılımcıların Yaşlarn ile Örgütsel Yaratıcılık Arasındaki Tukey Testi Sonuçları

Örgütsel Yaratıcılık

Tukey HSD ${ }^{\mathrm{a}, \mathrm{b}}$

\begin{tabular}{lllll}
\hline & & \multicolumn{3}{c}{ Subset for alpha $=0.05$} \\
\cline { 3 - 5 } Yaş & $\mathbf{N}$ & $\mathbf{1}$ & $\mathbf{2}$ & $\mathbf{3}$ \\
\hline $18-30$ & 240 & 131,0125 & 138,5603 \\
\hline $31-43$ & 116 & & 148,6111 \\
\hline $\begin{array}{l}44 \text { yaş ve } \\
\text { üzeri }\end{array}$ & 36 & & 1,000 & 1,000 \\
\hline Sig. & & 1,000 & & \\
\hline
\end{tabular}

Tablo 7. Katılımcıların Ĕ̆itim Durumları ile Kişilik Özellikleri Alt Boyutları ve Örgütsel Yaratıcılı̆̆a İlişkin Anova Testi Sonuçları

\begin{tabular}{|c|c|c|c|c|c|c|}
\hline \multicolumn{7}{|l|}{ ANOVA } \\
\hline & & \multirow{2}{*}{$\begin{array}{l}\text { Kareler } \\
\text { lamı }\end{array}$} & Top- & \multicolumn{2}{|l|}{ Ortalama } & \multirow[b]{2}{*}{$\mathbf{p}$} \\
\hline & & & $\mathrm{df}$ & Karesi & $\mathbf{F}$ & \\
\hline \multirow[t]{3}{*}{ Nörotiklik } & Gruplar Aras1 & 8,094 & 2 & 4,047 & 252 & ,777 \\
\hline & Gruplar İçi & 6243,475 & 389 & 16,050 & & \\
\hline & Toplam & 6251,569 & 391 & & & \\
\hline \multirow[t]{3}{*}{ Dışa Dönüklük } & Gruplar Aras1 & 390,956 & 2 & 195,478 & 9,622 & , 000 \\
\hline & Gruplar İçi & 7902,544 & 389 & 20,315 & & \\
\hline & Toplam & 8293,500 & 391 & & & \\
\hline \multirow[t]{3}{*}{ Açıklık } & Gruplar Arası & 114,999 & 2 & 57,499 & 2,460 & , 087 \\
\hline & Gruplar İçi & 9093,001 & 389 & 23,375 & & \\
\hline & Toplam & 9208,000 & 391 & & & \\
\hline \multirow[t]{3}{*}{ Uyumluluk } & Gruplar Arası & 50,163 & 2 & 25,082 & ,907 & 405 \\
\hline & Gruplar İçi & 10756,712 & 389 & 27,652 & & \\
\hline & Toplam & 10806,875 & 391 & & & \\
\hline \multirow[t]{3}{*}{ Sorumluluk } & Gruplar Arası & 317,552 & 2 & 158,776 & 4,017 & ,019 \\
\hline & Gruplar İçi & 15376,642 & 389 & 39,529 & & \\
\hline & Toplam & 15694,194 & 391 & & & \\
\hline Örgütsel & Gruplar Arası & 4352,997 & 2 & 2176,498 & 5,768 & ,003 \\
\hline \multirow[t]{2}{*}{ Yaratıcılık } & Gruplar İçi & 146785,564 & 389 & 377,341 & & \\
\hline & Toplam & 151138,561 & 391 & & & \\
\hline
\end{tabular}

Tablo 7 'de eğitim ile örgütsel yaratıcılık ve kişilik tarzlarına ilişkin Anova testi sonuçları verilmiştir. Örgütsel yaratıcılık ile kişilik tarzlarından dışa dönüklük ve sorumluluk alt boyutlarında $p<0,05$ bulunmuştur. 
Farklılığın hangi gruptan kaynaklandığını anlayabilmek için Tukey testi sonuçlarına bakılması gerekmektedir.

Tablo 8. Katılımcıların Eğitimleri ile Dışa Dönüklük Boyutu Arasındaki Tukey Testi Sonuçları

Dişa Dönüklük

Tukey HSD ${ }^{\mathrm{a}, \mathrm{b}}$

\begin{tabular}{llll}
\hline & & \multicolumn{2}{l}{ Subset for alpha $=0.05$} \\
\cline { 3 - 4 } Eğitim & $\mathbf{N}$ & $\mathbf{1}$ & $\mathbf{2}$ \\
\hline İlköğretim & 150 & 28,1733 & 29,8725 \\
\hline Ortaöğretim & 149 & & 30,5914 \\
\hline Ön lisans/lisans & 93 & 1,000 &, 420 \\
\hline Sig. & &
\end{tabular}

\%95 güven düzeyinde katılımcıların eğitimleri ile dışa dönüklük arasındaki anlamlı farklılık ön lisans ve lisans eğitimi alan gruptan kaynaklanmaktadır. Ön lisans ve lisans eğitimi alanların daha dışa dönük bir kişilik tarzı olduğu söylenebilir. Eğitim seviyesi yükseldikçe dışa dönüklük de artmaktadır.

Tablo 9. Katılımcıların Eğitimleri ile Sorumluluk Boyutu Arasındaki Tukey Testi Sonuçları

Sorumluluk

Tukey HSD ${ }^{\mathrm{a}, \mathrm{b}}$

\begin{tabular}{lccc}
\hline & & \multicolumn{2}{c}{ Subset for alpha $=0.05$} \\
\cline { 3 - 4 } Eğitim & $\mathbf{N}$ & $\mathbf{1}$ & $\mathbf{2}$ \\
\hline İlköğretim & 150 & 27,2000 & 28,9785 \\
\hline Ortaöğretim & 93 & 28,9785 & 29,0940 \\
\hline Ön & 149 & &, 989 \\
lisans/lisans & &, 067 & \\
\hline Sig. & &
\end{tabular}

Sorumluluk alt boyutunda dışa dönüklük alt boyutunda olduğu gibi anlamlı farklılık ön lisans ve lisans eğitimi almış gruptan kaynaklanmaktadır. Eğitim seviyesi arttıkça sorumluluk kişilik tarzı da artmaktadır. 
Tablo 10. Katılımcıların Ĕ̆itimleri ile Örgütsel Yaratıcılık Boyutu Arasındaki Tukey Testi Sonuçlan

\begin{tabular}{|c|c|c|c|c|}
\hline \multicolumn{5}{|c|}{ Örgütsel Yaratıcılık } \\
\hline \multicolumn{5}{|l|}{ Tukey HSD ${ }^{a, b}$} \\
\hline \multirow[b]{2}{*}{ Eğitim } & & & Subset $\mathrm{f}$ & 0.05 \\
\hline & & $\mathbf{N}$ & 1 & 2 \\
\hline İlköğretim & 150 & & 130,6467 & \\
\hline Ortaöğretim & 149 & & & 137,1745 \\
\hline Ön lisans/lisans & 93 & & & 137,9570 \\
\hline Sig. & & & 1,000 & 946 \\
\hline
\end{tabular}

Tablo 10 incelendiğinde örgütsel yaratıcilığ en yüksek grubun ön lisans ve lisans eğitimi almış olan grup, örgütsel yaratıcılığı en düşük olan grupta ilköğretim eğimi almış olan grup olduğu görülmektedir. Eğitim seviyesi arttıkça örgütsel yaratıcılık düzeyi de artmaktadır.

Araştırmanın bağımsız değişkeni olan kişilik özellikleri ile alt boyutları olan; nörotiklik, dışa dönüklük, gelişime açıklık, uyumluluk, sorumluluk ve bağımlı değişken olan örgütsel yaratıcılığa ilişkin korelasyon değerleri Tablo 11'de verilmektedir.

Kişilik tarzları alt boyutlarıyla örgütsel yaratıcılık arasındaki ilişkiyi belirlemek amacıyla korelasyon analizi yapılmıştır. Tablo 11'deki bulgulara göre örgütsel yaratıcılık ile kişilik alt boyutlarından olan sorumluluk arasında $\left(\mathrm{r}=, 652^{* *}\right)$; dişa dönüklük arasında $\left(\mathrm{r}=, 604^{* *}\right)$; uyumluluk arasında $\left(\mathrm{r}=, 587^{* *}\right)$ ve deneyime açıklık arasında $\left(\mathrm{r}=, 207^{* *}\right)$; pozitif yönde anlamlı bir ilişki bulunmuştur. $r$ değeri 1'e doğru yaklaştıkça korelasyon daha kuvvetli olmaktadır. Bu doğrultuda örgütsel yaratıcılık ile en yüksek korelasyon sırasıyla; sorumluluk, dışa dönüklük, uyumluluk ve deneyime açıklık arasındadır.

Elde edilen bu veriler 1şığında $\mathrm{H} 2, \mathrm{H} 3, \mathrm{H} 4$ ve $\mathrm{H} 5$ kabul edilirken $\mathrm{H} 1$ reddedilmektedir. 
Tablo 11. Kişilik Özellikleri Alt Boyutları ve Örgütsel Yaratıcılık Değişkenine İlişkin Korelasyon Analizi Sonuçları

\begin{tabular}{|c|c|c|c|c|c|c|c|}
\hline \multicolumn{8}{|l|}{ Korelasyon } \\
\hline & & Nörotiklik & Dişa D. & Geliş. A. & Uyum. & Sorml. & Ö. Y. \\
\hline \multirow[t]{3}{*}{ Nörotiklik } & Krlsyn & 1 & & & & & \\
\hline & Sig. (p) & & & & & & \\
\hline & $\mathrm{N}$ & 392 & & & & & \\
\hline \multirow{3}{*}{$\begin{array}{l}\text { Dişa } \\
\text { Dönüklük }\end{array}$} & Krlsyn &,- 026 & 1 & & & & \\
\hline & Sig. (p) & 607 & & & & & \\
\hline & $\mathrm{N}$ & 392 & 392 & & & & \\
\hline \multirow{3}{*}{$\begin{array}{l}\text { Gelişime } \\
\text { Açılık }\end{array}$} & Krlsyn &,- 082 & ,097 & 1 & & & \\
\hline & Sig. (p) & 104 & ,055 & & & & \\
\hline & $\mathrm{N}$ & 392 & 392 & 392 & & & \\
\hline \multirow[t]{3}{*}{ Uyumluluk } & Krlsyn & ,011 & $282^{* *}$ &, $232^{* *}$ & 1 & & \\
\hline & Sig. (p) & 827 & ,000 & ,000 & & & \\
\hline & $\mathrm{N}$ & 392 & 392 & 392 & 392 & & \\
\hline \multirow[t]{3}{*}{ Sorumluluk } & Krlsyn &,- 059 & $387^{* *}$ & $168^{* *}$ &, $367^{* *}$ & 1 & \\
\hline & Sig. (p) & ,247 & ,000 & ,001 & ,000 & & \\
\hline & $\mathrm{N}$ & 392 & 392 & 392 & 392 & 392 & \\
\hline \multirow{3}{*}{$\begin{array}{l}\text { Örgütsel } \\
\text { Yaratıcılık }\end{array}$} & Krlsyn & ,044 & $604^{* *}$ & $207^{* *}$ &, $587^{* *}$ & $652^{* *}$ & 1 \\
\hline & Sig. (p) & ,381 &, 000 &, 000 &, 000 &, 000 & \\
\hline & $\mathrm{N}$ & 392 & 392 & 392 & 392 & 392 & 392 \\
\hline
\end{tabular}

**. Correlation is significant at the 0.01 level (2-tailed).

\section{Sonuç ve Öneriler}

Araştırma sonuçlarına göre; kadınların erkeklere göre kişilik tarzı olarak daha uyumlu, daha çok sorumluluk sahibi ve örgütsel anlamda daha yaratıcı olduğu; evli katılımcıların kişilik özellikleri bakımından dışadönük, gelişime açık, uyumlu ve sorumluluk sahibi olduğu; 44 yaş ve üzeri yaş grubundaki katılımcıların uyumluluk ve sorumluluk kişilik özelliğini diğer yaş gruplarına göre daha çok sergilediği, yaş ile birlikte uyumluluk ve sorumluğun arttığı; ön lisans ve lisans eğitimi alanların daha dişa dönük ve sorumluluk sahibi bir kişilik tarzı olduğu belirlenmiştir.

Örgütsel yaratıcılığı daha yüksek olan katılımcılar ise; erkek, evli, 44 yaş ve üzeri ile ön lisans ve lisans eğitimi almış kişilerdir. 
Kişilik tarzları boyutlarından örgütsel yaratıcılı̆̆ı en çok etkileyen boyutlar sirasıyla; sorumluluk, dişa dönüklük, uyumluluk ve deneyime açıklıktır. Örgütsel yaratıcılık ile bir tek nörotiklik alt boyutu arasında ilişki bulunmamaktadır. Kişilik tarzlarından en çok sorumluluk örgütsel yaratıcılık üzerinde etkili olmaktadır. Sorumluluğu yüksek işgörenler beklenenin üzerinde bir performansta çalışmayı, kararlı durmayı, dikkatli olmayı, sorunlarla mücadele edebilmek için her şeye hazırlıklı olmayı, dikkatlice düşünmeyi ve başlanmış olan bir işi yarım bırakmama eğilimindedirler. Sorumluluğu yükselen kişilerin motivasyon ve iş tatminleri de yükselmektedir.

Her ne kadar yukarıdaki sonuçlara ulaşılmışsa da, çalışmanın bazı kısıtları da bulunmaktadır. Öncelikle bu çalışma, tek bir işletmedeki çalışanlar üzerinde gerçekleştirilmiştir ve seçilen örneklem sayısı kuramsal açıdan yeterli görülse dahi genelleme yapılacak büyüklükte değildir. Ayrıca kişilik özellikleri ve örgütsel yaratıcılık konularına ek olarak farklı bir değişkenle aracılık etkisi araştırılabilir. Bu nedenle, başka çalışmalarla desteklenebilir. 


\title{
EXTENDED ABSTRACT
}

\section{Which Personality Is More Effective On Organizational Creativity?}

\author{
Fatma Yilmaz
}

\author{
Erzincan Binali Yaldırım Universtiy
}

Organizational creativity is the application of creative thinking as a whole in all units and processes of institutions. Organizational creativity is very important for enterprises to create long term competitive advantage. In this study, it is aimed to determine the effects of employee personality traits on organizational creativity. The sample of the study consists of 392 participants working in a service enterprise.

Personality Concept: Personality concept in its simplest form; An what separates a person from other people is the behavior of that individual ". Psychological factors that affect people's behaviors in a distinctive and permanent way also express the concept of personality (Şahin and Aksu, 2015,p.136). Five-Factor Personality Traits: Norman Anderson used 555 adjectives to describe personality traits. In his research, he asked university students to determine how much they could love the person who had each of the adjectives. In this study he conducted in 1960, it was seen that the most popular personality trait was iyet sincerity.. According to the results of the study, the most prominent 60-person feature is ranked according to the most popular and the most unpopular; sincere, honest, insightful, loyal, realistic and reliable adjectives are the first six. Unrealistic, dishonest, cruel, bad, fraudulent, false features are the six unpopular features (Güney, 2011,p.55-56). Cüceloğlu, in Turkish, used for the expression of personality traits used in the estimated 10-15 thousand stated that the adjective used (Cüceloğlu, 2005, p.418). All studies on personality are essentially based on five factors personality theory (Şentepe and Güven, 2015, p.28). Five factor personality theory; In the measurement of personality based on the "Characteristics Approach maktad, it makes use of various 
adjectives for individuals to express themselves and other individuals (Doğan, 2013,p.57). In 1966, Cattel tried to explain personality in 16 dimensions and Eysenk in 2 dimensions: introvert and extroversion. Robert R. McCrea and Paul T. Costa's work in 1978, in 1980, the same researchers in the extroversion and extroversion dimensions of openness to the third dimension of the experience; In 1987, they introduced the "Five Great Factors" theory by adding the fourth and fifth dimensions of compliance and responsibility (conscience) and expanding their studies in line with the criticisms directed to these dimensions (Sayın and Aslan, 2005). The dimensions of the five-factor theory are: neuroticism, extraversion, openness to development, compliance, and self-discipline.

Creativity; problems, deficiencies, lack of information, being sensitive to incompatibilities and difficulties to identify, search for solutions, to make various estimates, to develop ideas for deficiencies, and then to reveal the result (Sungur, 1992,p.20). Although the concept of creativity is the basis of human beings, the main source of enterprises is the concept of being an individual and the enterprises are managed by people in the organizational dimension (Bharadwaj and Menon, 2000,p.425). Organizational creativity; It is defined as being able to mobilize the existing potentials of the employees and to spread the creativity ability to the entire organization in a way that covers all the employees (Gürüz and Özdemir, 2006,p.366). Organizations need creativity to adapt to the rapidly changing environment and keep the organization alive. Because, businesses that lack creativity in rapidly changing environments face extinction (Fisk, 2011,p.58).

The aim of this study is to determine the effect of personality traits on organizational creativity and to investigate and reveal the effects of demographic traits on personality styles. The findings of the research will constitute a data for future research on the subject. The study was conducted on a service sector in Erzincan. Sampling Easy sampling method was used in the study. 392 of the questionnaires distributed in the research were returned and evaluated.

Survey method was used as a data collection tool in the research. The questionnaire consists of 86 questions. In the first part of the questionnaire, 4 questions about personal information; In the second part, there are 
44 questions about personality traits and 38 questions about organizational creativity.

Fact Five Factor Inventory Ben, Benet-Martinez and John faktör. The scale has five sub-dimensions: neuroticity, extroversion, openness to development, compliance and responsibility. The 38-item organizational creativity scale was developed by Balay (2010). The scale consists of three dimensions: individual creativity, managerial creativity and social creativity. The effects of personality traits on organizational creativity were tried to be determined by the survey. The model of our study is shown in Figure 1. Personality traits were evaluated as independent variable and organizational creativity was evaluated as dependent variable.

According to the results of the research; that women are more adaptive, more responsible and more creative in terms of personality than men; married participants are extraverted, open to development, harmonious and responsible in terms of personality traits; Participants in the age group of 44 years and over exhibited the compliance and responsibility personality traits more than other age groups, and compliance and responsibility increased with age; It was determined that the associate and undergraduate students have a more extroverted and responsible personality style. The participants with higher organizational creativity; men, married, 44 years of age or older and have undergraduate and graduate education.

The dimensions that affect organizational creativity the most are personality styles; responsibility, extroversion, compatibility and openness to experience. There is no relationship between organizational creativity and a single neuroticism sub-dimension. Responsibility of personality styles mostly affects organizational creativity. Employees with high responsibilities tend to work above expected performance, to be determined, to be careful, to be prepared for everything to be able to tackle problems, to think carefully and not to abandon a work that has already begun. Motivation and job satisfaction of the people who have increased responsibility also increases. 


\section{Kaynakça / References}

Balay, R. (2010). Öğretim elemanlarının örgütsel yaratıcılık algıları. Ankara Üniversitesi Ĕ̆itim Bilimleri Fakültesi Dergisi, 43(19), 41-78.

Barron, F. ve Harrington, D. M. (1981). Creativity, intelligence, and personality. Annual Review Psychology, 32, 439-476.

Barrick, M. R. ve Mount, M. K. (1991). The big five personality dimensions and job performance: a meta-analysis. Personnel Psychology, 44, 126.

Benet-Martinez, V. ve John, O. P. (1998). Los cinco grandes across cultures and ethnic groups: multitrait-multimethod analyses of the big five in Spanish and English. Journal of Personality and social Psychology, 75(3), 729.

Bharadwaj, S. ve Menon, A. (2000). Making innovation happen in organizations: individual creativity mechanism, Organizational Creativity Mechanism or Both?. Journal of Product Innovation Mangement, 17, 424-434.

Bono, J. E., Boles, T. L., Judge, T. A. ve Lauver, K. J. (2002). The role of personality in task and relationship conflict. Journal of Personality.70(3), 1311-1344.

Bulut, S. S. (2017). Beş faktör kişilik özellikleri, stresle başa çıma ve depresyon arasındaki ilişkiler: Gazi Eğitim Fakültesi örneği. Uluslararası Türkçe Edebiyat Kültür Eğitim Dergisi, 6(2), 1205-1221.

Costa, P. T. J. R. ve Mccrae, R. R. (1992). Four ways the five factors are basic. Personality and Individual Differences, 13, 653-665.

Costa, P. T., Mccrae, R. R. ve Dye, D. A. (1991). Facet scales for agreeableness and conscientiousness; a revision of the neo personality inventory. Personality and Individual Differences, 12(9), 887-898.

Cüceloğlu, D. (2005). İnsan ve davranışı. İstanbul:Remzi Kitapevi.

Deniz, A. ve Erciş, A. (2008). Kişilik özellikleri ile algılanan risk arasındaki ilişkilerin incelenmesi üzerine bir araştırma. İktisadi ve İdari Bilimler Dergisi, 22(2), 301-330.

Doğan, T. (2013). Beş faktör kişilik özellikleri ve öznel iyi oluş. Doğuş Üniversitesi Dergisi, 14(1), 56-64.

Eroğlu, F. (2006). Davranış bilimleri. İstanbul: Beta Yayınları. 
Feist, G. J. (1998). A meta-analysis of personality in scientific and artistic creativity. Personality and Social Psychology Review, 2, 290-309.

Fisk, P. (2011). Yaratıcı deha,. N. ÖzataÇev, İstanbul: MediaCat.

Garcia, D. (2011). The affective temperaments: Differences between adolescents in the big five model and cloninger's psychobiological model of personality. Springer Science Business Media B. V, Journal Happiness Stud13, 999-1017.

Goldberg, L. R. (1990). An alternative "description of personality": the bigfive factor structure. Journal of Personality and Social Psychology, 59(6), 1216-1229.

Göksel, A. (2003). Personel güçlendirme, çağdaş işletme teknikleri, (B. Bumin ed.) Ankara: Gazi Kitabevi,

Güney, S. (2011). Örgütsel davranış. Ankara: Nobel Yayın Dağıtım.

Gürüz, D. ve Özdemir-Yaylacı, G. (2007). Insan kaynakları yönetimi, 4. Baskı. İstanbul: MeciaCat Kitapları.

Hurtz, G. M. ve Donovan, J. J. (2000). Personality and job performance: The big five revisited. Journal of Applied Psychology, 85, 869-879.

Köknel, Ö. (1997). Kaygıdan mutluluğa kişilik, İstanbul:Altın Kitaplar.

Lounsbury, J., Sundstrom, W., Loveland, E., Gibson, J. L. ve Lucy W. (2002). Broad versus narrow personality traits in predicting academic performance of adolescents. Learning and Individual Differences, 14(1), 65-75.

Luthans, F. (1995). Organizational behavior. New York: McGraw Hill Co. Marşap, A. (1999). Yaratıcı liderlik. Ankara: Öncü Kitapları.

Mccrae, R. R. ve John, O. P. (1992). An introduction to the five-factor modeland its applications. Journal of Personality, 60(2), 175-215.

Patrick, H. A. (2010). Personality traits in relation to job satisfaction of management educators. Asian Journal of Management Research, 1(1), 239-249.

Polat, S. (2009). Öğretmen adaylarının çok kültürlü eğitime yönelik kişilik özellikleri. International Online Journal of Educational Sciences, 1(1), 154-164.

Sayin, A. ve Aslan, S. (2005). Duygudurum bozuklukları ile huy, karakter ve kişilik ilişkisi. Türk Psikiyatri Dergisi, 16(4), 276-283.

Somer, O. (1998). Türkçe'de kişilik özelliği tanımlayan sıfatların yapısı ve beş faktör modeli. Türk Psikoloji Dergisi, 13(42), 17-312. 
Sungur, N.(1992). Yaratıcı düşünce. İstanbul: Özgür Yayın Dağıtım, Sümer, N., Lajunen, T. ve Özkan, T. (2005). Big five personality traits as the distal predictors of road accident. Traffic and Transport Psychology: Theory and Application, 215, 215-227.

Şahin, F., ve Danışman, Ş. (2017). Yaratıcı kişilik özellikleri ölçeği: güvenilirlik ve geçerlik çalışması. Karabük Üniversitesi Sosyal Bilimler Enstitüsü Dergisi, 7(2), 747-760.

Şahin, S. ve Aksu, S. G. (2015). İdari göreve sahip akademisyenlerin kişilik özellikleri ile kullandıkları çatışma çözme stilleri ilişkisi: İzmir ili örneği. İşletme Fakültesi Dergisi, 16(2), 135-154.

Şentepe, A. ve Güven, M. (2015). Kişilik özellikleri ve dindarlık ilişkisi üzerine ampirik bir araştırma. Sakarya Üniversitesi İlahiyat Fakültesi Dergisi, 17(31), 28-44.

Tikici, M. ve Deniz, M. (1991). Örgütsel davranış. Malatya:Enstitü Yayınları, Woodman, R. W., Sawyer, J. E. ve Griffin, R.W. (1993). Toward a theory of organizational creativity. Academy of Management Review, 8(2), 293321.

Yelboğa, A. (2006). Kişilik özellikleri ve iş performansı arasındaki ilişkinin incelenmesi. ISGUC The Journal of Industrial Relations and Human Resources, 8(2), 196-217.

Yilmaz, E. ve Izgar, H. (2009). Examination of primary school teachers' job satisfaction with regards to organizational creativity withina a school contex. Elementary Education Online, 8(3), 943-951.

Zangwill, O. L. (2009). Modern psikolojinin gelişimi. İstanbul:Ötüken Neşriyat.

Zel, U. (2001). Kişilik ve liderlik. Ankara:Seçkin Yayıncılık.

\section{Kaynakça Bilgisi / Citation Information}

Yılmaz, F. (2019). Hangi kişilik özelliği örgütsel yaratıcılık üzerinde daha etkilidir?. OPUS-Uluslararası Toplum Araştırmaları Dergisi, $12(18$. UIK Özel Sayıs1), 167-192. DOI: 10.26466/opus.586879. 